\title{
$\checkmark$ Research Square \\ Factors associated with non-vaccination against measles among 12-23 months old children in Yirgachefe district of SNNPR, Ethiopia, 2016
}

Luna Habtamu Degife ( $\square$ lunahabt@gmail.com )

Ethiopian Public Health Institute https://orcid.org/0000-0002-4573-6439

\section{Yoseph Worku}

Saint Paul Hospital Millennium Medical College

Muse Tadesse

Ethiopian Public Health Institute

Research article

Keywords: Measles, Non vaccination, Risk factors

Posted Date: March 26th, 2020

DOI: https://doi.org/10.21203/rs.2.10399/v3

License: (1) (i) This work is licensed under a Creative Commons Attribution 4.0 International License.

Read Full License 


\section{Abstract}

Immunization is an effective and proven tool for controlling and eliminating life-threatening vaccine preventable infectious diseases. In Ethiopia 5\% of childhood mortalities are due to measles. Despite the availability of a safe and effective vaccine, measles outbreaks secondary to non-vaccination are occurring in southern Ethiopia especially in Yirgachefe district. This study was done to assess the risk factors associated with non-vaccination against measles. A Community-based unmatched case control study was conducted in Yirgachefe district from December 1-31, 2016.Cases were children in the age group of 12- 23 months of age who did not take measles vaccination and controls were children in the same age group who took at least one dose of measles vaccine. The study was done in 6 randomly selected kebeles and cases and controls were selected randomly by probability proportional to size sampling. A structured questionnaire was used for data collection. Statistical significance was interpreted using Odds ratio with $95 \%$ confidence interval and $P$ value $<0.05$.A total of 320 individuals $(107$ cases and 214 controls) were approached for interview with a response rate of $93.75 \%$. Of the cases, $57 \%$ were males and more than half fall in the 12-18 months age group. Knowledge regarding measles vaccination was also asked and among cases $72 \%$ heard about measles, $26 \%$ knew that all children should be vaccinated, $31 \%$ had awareness about the right age of vaccination, $60 \%$ agrees that measles is vaccine preventable and $65 \%$ knew that it is contagious. In multivariable logistic regression, Lack of Ante Natal Care follow up(ANC) (Adjusted Odds Ratio (AOR) $=3.57$; 95\% Confidence Interval (Cl): 1.22-10.44), lack of knowledge on the importance of vaccination, who should be vaccinated and if measles is contagious with an AOR and $\mathrm{Cl}$ of (AOR=6.81; 95\% Cl: 1.56-29.64), (AOR=4.29; 95\% $\mathrm{Cl}: 1.83-10.04)$ and (AOR=8.97; $95 \% \mathrm{Cl}$ : 3.15-25.58) respectively were independent risk factors. Education and awareness about measles and its immunization should be given to the community. Additionally, ANC follow up should also be strengthened.

\section{Background}

Immunization is an effective and proven tool for controlling and eliminating life-threatening infectious diseases. (1).

Accelerated immunization activities have had a major impact on reducing measles deaths. During 20002018, measles vaccination prevented an estimated 23.2 million deaths. Global measles deaths have decreased by $73 \%$ from an estimated 536000 in $2000 *$ to 142,000 in 2018. (2). Measles, one of the vaccine preventable diseases, is a highly contagious disease caused by a virus, which usually results in a high fever and rash, and can lead to blindness, encephalitis or death(3).

By the end of $2018,86 \%$ of children had received one dose of measles vaccine by their second birthday, and 171 countries had included a second dose as part of routine immunization and $69 \%$ of children received two doses of measles vaccine according to national immunization schedules.. Despite the availability of a safe and effective vaccine, measles remains one of the leading causes of death among young children globally(4). 
Under the Global Vaccine Action Plan, measles is targeted for elimination in five WHO Regions by 2020. Effective vaccination against the disease is helpful to achieve the elimination goal. The highly effective, safe and relatively inexpensive measles- containing vaccines protect individuals from infection, and their widespread use can completely stop the spread of the viruses in populations that achieve and maintain high levels of immunity(5).Between 2000 and 2014,measles vaccination resulted in 79\% drop in measles deaths worldwide making measles vaccine one of the best buys in public health (6).

Unvaccinated young children and pregnant women are at highest risk of measles and its complications, including death. Any non-immune person (who has not been vaccinated or was vaccinated but did not develop immunity) can become infected with measles(6). Studies showed that children who had not received measles vaccine were 35 times more likely to get infected (7).

According to the 2016 EDHS report, the measles vaccination coverage of Ethiopia and Southern Nations' Nationalities and Peoples' Region (SNNPR) was 54.3\% and 57.6\% respectively. Additionally, in 2014 WHO reported that the measles vaccination status of Ethiopia to be $70 \%$.However Federal Ministry of Health has reported an overall measles vaccination coverage above $90 \%$ in $2015 / 2016$ (8). Even though there is an improvement in the vaccination coverage, outbreaks still persists and in Ethiopia measles accounts for $5 \%$ of childhood mortality. It is probably common among the vaccine preventable diseases that occur repeatedly and mothers recognize it as a self-limited common childhood illness for which no medical care is often sought. Based on the Epidemiology of measles and burden of disease modeling, it is estimated that more than 1.5 million cases of measles and 70,000 deaths would occur in Ethiopia annually. In 2013, measles incidence was 7.2 cases per 100,000 populations and a total of 243 measles outbreaks were confirmed with 192 affected districts(9).

Ethiopia is committed to achieving the elimination of measles by 2020 in line with African region Resolution. Through implementation of the recommended strategies including strengthening routine immunization activities and accelerated measles control since 2002, there was steady progress in reducing morbidity and mortality from measles. Continuing measles outbreaks despite efforts to implement planned strategies are documented especially in SNNPR, Amhara and Oromia regions(9).In 2015, SNNPR regional health bureau had reported an outbreak in 2015.

The occurrence of outbreaks despite the improvement in vaccination may be due to ineffective cold chain management, low herd immunity or underreporting of the unvaccinated. Non vaccination can be a result of maternal factors, service related factors or factors associated with child characteristics. Therefore, the aim of this study is to assess the risk factors associated with non-vaccination against measles in Yirgachefe woreda.

\section{Objectives}

To assess factors associated with non-vaccination against measles in Yirgachefe District of Gedeo zone, SNNPR, Ethiopia. 


\section{Methods And Materials}

This study was conducted in Yirgachefe district of SNNPR. It is $395 \mathrm{Km}$ far from Addis Ababa, capital of the country. It is bordered in the south by Kochere, north by Wonago, east by Bule, and southeast by Gedeb districts(10). It has a total population of 257,489. Thirty-seven thousand five hundred ninetyfour $(37,594)$ of the population segment are children less than five years. The district is divided in to 33 kebeles (small administrative units) of which 2 are urban kebeles. The district's temperature is $5 \%$ Kola and 95\% Dega and Woyina Dega. In the district, there are 7 health centers, 31 health posts and 3 private clinics.

A Community-based unmatched case control study was conducted from December 1-31, 2016. 12-23 months' age group children in Yirgachefe district were the source population. Cases were children in the age group of 12-23 months of age who did not take measles vaccine while Controls were Children in the age group of 12-23 months and who took at least one dose of measles vaccine. Those children of mothers who neither have vaccination card nor remember if their child has taken measles vaccination or not were excluded from the study.

The sample size was generated using StatCalc in Epi-Info 7 statistical software. As shown in the table below, sample size was calculated for different risk factors from various literatures using 1:2 cases to control ratio, $5 \%$ margin of error, $95 \%$ confidence interval, $80 \%$ power, a non-response rate of $10 \%$ and a design effect of 1.5. Considering the time and resource allocated, assessing 478 households will not be feasible. Therefore, the second large sample size was taken. Hence, a total of $\mathbf{3 2 0}$ participants (107 cases and 214 controls) were included in the study (Table 01).

Multi stage sampling technique was used to obtain a representative study sample. There are a total of 31 rural and 2 urban kebeles in the district. In the first stage, 5 rural kebeles and 1 urban kebele were selected using simple random sampling technique. In each selected kebeles, the list and addresses of a child between the age group of 12-23 months with their measles vaccination status were pulled out from each kebele's health extension workers family folder. Age was ascertained and cross checked from both the health extension's family folders and caretakers' information. In the availability of birth certificate, it was verified through the certificate. Sampling frame was prepared for both cases and controls. By using probability proportional to size sampling, the number of cases and controls for each kebeles were calculated. Finally, from the total sampling frame, the calculated number of cases and controls were selected randomly using lottery method from each kebele (Fig.1).

Measles Vaccination status of children aged 12-23 months was the dependent variable. Socio demographic characteristics of mothers/caretakers, sex of child, birth order of child, place of residence, place of delivery, educational status of mother/ care taker and father, Maternal tetanus toxoid immunization status, Knowledge of mothers/caretakers about vaccinations and its importance, family size, Parity, Time of travel to reach the nearest health facility, monthly family income, ANC and PNC follow up of a mother, availability of immunization services, availability of health extension worker, and past Expanded Program on Immunization (EPI)experiences were the independent variables. 
A structured interviewer administered questionnaire initially developed in English and later translated into the local language (Gedeo) was used for data collection. The questionnaire was adapted from various literature sources. The content of the questionnaire include socio-demographic and economic characteristics, maternal and child factors and health service related factors.

Vaccination status of a child and a mother was recorded from the available immunization card or by asking the mother or care taker if the card is not available. The data collector helped the mother or care taker to remember by telling her the time of administration or the site of injection. For a child with immunization card, the information on the doses and types of vaccines received was recorded from the card. Additionally, verbal information from the mother/caretaker about the doses taken was recorded.

The questionnaire was pretested in one kebele of Wonago district to determine its appropriateness on the local context. Diploma nurses and health extension workers from other unselected kebeles were recruited as data collectors and health officers were assigned as supervisors. All the data collectors and the supervisors were trained intensively for about three days about the objective of the study, on how to select households, how to approach each interviewee, how to ask question, regarding ethical issues, data quality and how to collect important information.

During data collection every questionnaire filled by data collectors was checked daily by field supervisors for its completeness. Incomplete questionnaires were completed by revisiting those households. Data collectors filled information regarding child vaccination history based on vaccination card (if available) and they gave enough time for mothers/caretakers to bring the card. Additionally, the principal investigator checked the filled questionnaire and gave feedback for field supervisors every day prior to data entry.

The data was entered, cleaned and edited using EPI-Info 7 and transferred to SPSS version 20 for further analysis. Frequencies, means and percentages were calculated and differences in proportions were calculated using the Chi-square test with $5 \%$ significance level. Associations between factors and vaccination status were tested first by the chi-square test. In order to investigate relative importance of the variables in relation to the dependent factor and any confounding between them, they were fitted together in a binary logistic regression model to identify independent factors. Those variables that come significant in the bivariate analysis were fitted to a multivariable analysis followed by a backward stepwise procedure to control confounding. Additionally, variables with $p$ value $<0.2$ were entered to the final model to avoid confounding. Statistical significance was interpreted using Odds ratio with $95 \%$ confidence interval and $\mathrm{P}$ value $<0.05$.

Ethical approval was obtained from Saint Paul's Hospital Millennium Medical College institutional review board. A formal letter was also submitted to all the responsible offices (SNNPR Health Bureau, Gedeo Zone Health Department and Yirgachefe Health office). Prior to data collection, informed verbal consent was gained from parents or guardians. All respondents were free to withdraw from the study at any time without any consequences. Confidentiality was assured and no personal details were recorded or 
produced on any documentation related to the study. No one was obliged to participate unless otherwise agreed to take part.

\section{Operational Definitions}

Accessibility of vaccination Services: Opportunity to get immunization services with in short radius (less than 5 kilometers).

Vaccination: The administration of a vaccine to stimulate a protective immune response that will prevent disease in the vaccinated person if contact with the corresponding infectious agent occurs subsequently.

Vaccinated: A child who received at least one dose of MCV (measles containing vaccine) according to information from vaccination cards or from mothers' (care givers') verbal reports.

Unvaccinated: A child who did not receive any dose of MCV according to information from vaccination cards or from mothers' (care giver's) verbal reports.

Vaccination Coverage: Proportion of children who took measles vaccination.

Non Professional attendant: Traditional birth attendants(TBAs) and those attendants who didn't take any formal training.

\section{Result}

\section{Socio Demographic characteristics}

A total of 300 individuals (100 cases and 200 controls) were approached for interview. Children's caretakers were interviewed and the response rate was $93.75 \%$. More than half of the cases and controls fall in the 12-18 months age group and the mean and median age was 17.84 months and 18 months respectively with a SD of 3.94 . Regarding birth order, $40 \%$ of cases and $38 \%$ of controls were fourth or above child for their mothers. The mean and median income of the interviewees was 400 and 300 birr respectively with a Standard Deviation (SD) of 436.04 birr. About two third of cases (70\%) and controls $(62.5 \%)$ caretaker's were illiterate (Table 02)..

\section{Maternal behavior related characteristics}

Maternal behavior related factors regarding measles immunization were also assessed and out of the total caretakers of cases and controls, $72 \%$ and $92.5 \%$ respectively heard about measles vaccination, of which $86 \%$ got the information from health professionals. Participants were also asked whether all children should be vaccinated and only $26 \%$ of the cases mothers/caretakers answered yes. Of the cases mothers/caretakers, only $31 \%$ had awareness about the right age of vaccination. Moreover, interviewees were also asked if vaccinating a child was important and its benefit. More than two third of the cases and almost all of the controls mothers/caretakers agreed that vaccination is important. On the other hand, 
$60 \%$ cases mothers/caretakers agreed that measles is vaccine preventable and $65 \%$ of cases mothers/caretakers knew that it is contagious (Table 03).

\section{Health service-related factors associated with measles vaccination}

The nearest health facility in $84 \%$ of the cases and $78 \%$ of controls kebele provide routine immunization. Health extension workers live in almost all cases and controls kebele. Forty five percent (45\%) of the cases mothers/caretakers will walk $15-30$ min to reach the nearest health facility while only $24 \%$ took more than one hour.

Only around a quarter $(23 \%)$ of the cases mothers/caretakers had vaccination card. However, vaccination card was available in $79 \%$ of the control's household. Moreover $25 \%$ of cases and $33 \%$ of controls experienced delay in other EPI services. Additionally, $45 \%$ of the cases mothers/caretakers had ANC follow up while more than three fourth of the control's mothers/caretakers visited the health facility during their pregnancy. On the other hand, $30 \%$ of the cases and $56 \%$ of the control's mothers/caretakers had PNC follow-up.

Regarding place of delivery, $73 \%$ of cases mothers/caretakers gave birth to their last child in their home and $67 \%$ were attended by non-professional attendants. (Table 04 ).

\section{Independent predictors of non-immunization against measles}

In Bivariate analysis, 9 variables: religion, availability of vaccination card, if a child was ever vaccinated, ANC follow up, TT vaccine, place of delivery, birth attendant, PNC follow up, heard about measles vaccination, knowledge about right age of vaccination, if measles is vaccine preventable and contagious, importance and benefit of vaccination, were significant.

The variables that showed statistical significant in the bivariate analysis, variables with $p$ value less than 0.2 and variables that were significant in most previous studies were further analyzed in multivariable logistic regression to adjust for potential confounders and to identify independent factors that affect measles vaccination.

In multivariable analysis, knowing if vaccinating a child is important, having ANC follow up, knowledge if all children should take measles vaccine and if measles is contagious were independent risk factors related to child's non vaccination against measles (Table 05).

\section{Discussion}

The current study revealed that the odds of mother's who had ANC follow up during their pregnancy were 3.57 times greater to vaccinate their child against measles when compared to those who did not have ANC follow up. This finding is consistent with studies done in Ambo, Machakal, Sinana and Sekota zuria district $(11,7$ and 19,21). According to a study in Machakal, children who were born from mothers who had no antenatal care visit during pregnancy were 2.5 times more likely to default to complete 
vaccination compared to infants who were born from mothers who had antenatal care visit during pregnancy (7). Additionally, the study in Ambo found that Children of mother who had ANC were 2.1 times more likely to vaccinate their child than those with no follow up (11). Moreover, in Sinana it was also identified that mothers/caretakers who had ANC visit were more likely to vaccinate their children (19). In Sekota Zuria of Northern Ethiopia it was also found that Mothers' ANC follow-up positively influenced the immunization status at least three times compared to mothers who did not attend ANC at all (21). These findings imply the increased probability that mothers who had ANC follow up may have the chance to discuss with health professionals and get information about measles vaccination. Additionally, it shows the health seeking behavior of the mother.

Knowledge on measles immunization was found to be one of the determinants of vaccination against the disease. This study identified that the odds of mothers/caretakers who didn't know that all children should be vaccinated against measles were 4.29 as great as the odds among the vaccinated children. Similar study from Sinana has also identified that children whose mothers have sufficient knowledge on immunization were twice more likely to be fully vaccinated than whose mother had little knowledge (19).In addition to this, from a study in Wonago, it was found that Knowledge regarding measles vaccine and schedule of polio vaccines were predictors of child immunization completion(20). Moreover, maternal education was a predictor of childhood immunization status in a study in Sekota zuria (21). A study from Mecha has also revealed that those mothers who have good knowledge on vaccination were more likely to fully vaccinate their child (14). This is due to the fact that education in measles vaccination could directly enhance a health seeking behavior of the mothers.

Caretakers/mothers knowledge if vaccinating a child is important was another identified risk factor associated with vaccination against measles. According to this study the odds that being unvaccinated against measles was because of mothers/caretaker's lack of knowledge on the importance of vaccination was 6.81 as compared to being vaccinated against measles. In consistence to this, a study in Arbaminch revealed that mothers with lack of knowledge about immunization benefits are more likely to vaccinate their children (13). This may be due to the fact that mothers who have knowledge about measles vaccination will probably vaccinate their child.

Participants were also asked if they knew that measles was contagious and $35 \%$ of the cases have no awareness on it while only $9 \%$ of the controls gave the answer no. The odds are 8.97 times greater given those children of caretakers/mothers who don't know that measles is contagious will be unvaccinated against measles compared to those born from mothers who knew measles is contagious. Coherently in a study in Sekota zuria,it was stated that the role of maternal education was an important predictor of immunization (21). Caretakers who have knowledge on measles contagiousness may seek health service in case of the disease and are likely to vaccinate their child against it.

None of the socio demographic factors have become significant in this study. Consistently according to the study in Ambo, mother's socio demographic characteristics were not significant (11). However maternal education was an important predictor in studies from Arbaminch and Somali $(12,13)$. 
Additionally, child age and parity were determinants of vaccination in a study in Machakal (7). This inconsistency may be due to sample size and study area difference.

Recall bias is one of the major limitations of the study. As information on vaccination status was collected from both vaccination card and mothers/caretaker's information, recall bias is likely to occur and cases and controls could be misclassified. Additionally, the study was not supported by qualitative study to explore detail reasons of mothers/caretakers for not vaccinating their child.

\section{Conclusions And Recommendations}

The result of this study identified that factors associated with non-immunization against measles are mostly related to maternal characteristics. ANC follow up, knowing if vaccination is important and if all should be vaccinated were identified as risk factors for non-vaccination. Additionally, awareness if measles is contagious was another predictor associated with non-immunization of children against measles.

Therefore, education and awareness should be given about measles immunization. Additionally, health professionals should give information for the community on measles. Health professionals should give additional information on vaccination for pregnant mothers that come to health facility for pregnancy care. Moreover, more emphasis should be given on ANC utilization of mothers as it has a great role to curb non vaccination against measles.

\section{Acronyms And Abbreviations}

$\begin{array}{ll}\text { ANC } & \begin{array}{l}\text { Ante Natal Care } \\ \text { AOR }\end{array} \\ \text { BCG } & \begin{array}{l}\text { Adjusted Odds Ratio } \\ \text { Bl }\end{array} \\ \text { COR } & \text { Confillus Calmette Guerin Vaccine Interval } \\ \text { EPI } & \text { Crude Odds Ratio } \\ \text { FMOH } & \text { Expanded program on Immunization } \\ \text { HEWs } & \text { Federal Ministry of Health } \\ \text { HF } & \text { Health Extension Workers } \\ \text { MCV } & \text { Health Facility } \\ \end{array}$


NGOs

SD

SIA

SNNPR

TT
Non Governmental Organizations

Standard Deviation

Supplemental Immunization Activities

Southern Nations' Nationalities and People's Region

Tetanus Toxiod

\section{Declarations Section}

\section{Ethics approval and consent to participate}

Ethical clearance was obtained from Saint Paul's Hospital Millennium Medical College. A letter was written for SNNP regional health bureau in order to obtain approval on the data collection. An informed written consent was obtained from all parents of the study participants. Confidentiality of information was assured and ensured. Participants were treated with respect and willingly participated in the study with no payment or cohesion.

\section{Consent for publication}

Not Applicable.

\section{Availability of data and materials}

The datasets used and/or analyzed during the current study are available from the corresponding author on reasonable request.

\section{Competing interests}

There is no conflict of interest.

\section{Funding}

Saint Paul's Hospital Millennium Medical College was the funding organization. The study was done as partial fulfillment of Master's degree.

\section{Authors' contributions}

LHD, the corresponding author, was the major contributor in preparing the manuscript. YW supported in the analysis and interpretation of the data and revised the manuscript critically for important intellectual contents. MT contributed a lot in the conception, revision and approval of the final version of the manuscript. All the authors agreed to be accountable for all aspects of the work in ensuring that 
questions related to the accuracy or integrity of any part of the work are appropriately investigated and resolved. All authors have approved the final manuscript.

\section{References}

1. http://www.who.int/topics/immunization/en/. Accessed on February 2020

2. https://www.who.int/news-room/fact-sheets/detail/measles Accessed on February 2020

3. https://wwwnc.cdc.gov/travel/diseases/measles Accessed on February 2020

4. https://www.who.int/en/news-room/fact-sheets/detail/immunization-coverage Accessed on February 2020

5. WHO. Global measles and rRubella Strategic plan. 2012-2020

6. http://www.who.int/mediacentre/factsheets/fs286/en/). Accessed on February 2020

7. Yenit MK, Assegid S, Abrha H. Factors Associated With Incomplete Childhood Vaccination among Children 12-23 Months of Age in Machakel Woreda , East Gojjam Zone: A Case Control Study. 2015;2(4):2-7.

8. CSA. Ethiopian Demographic and Health Survey, Ethiopia, 2016.

9. Akalu HB. Journal of Tropical Diseases Review on Measles Situation in Ethiopia; Past and Present. 2015;4(2):2-7.

10. https://en.wikipedia.org/wiki/Yirgachefe_(woreda)). Accessed on February 2020

11. Etana B, Deressa W. Factors associated with complete immunization coverage in children aged 12 23 months in Ambo Woreda, Central Ethiopia [Internet]. BMC Public Health. BMC Public Health; 2012. p. 1.

12. Mohamud AN, Feleke A, Worku W, Kifle M, Sharma HR. Immunization coverage of 12 - 23 months old children and associated factors in Jigjiga District, Somali National Regional State, Ethiopia. 2014;1-9.

13. Animaw W, Taye W, Merdekios B, Tilahun M, Ayele G. Expanded program of immunization coverage and associated factors among children age $12-23$ months in Arba Minch town and Zuria. 2014;14(1):1-10.

14. Debie A, Taye B. Assessment of fully vaccination coverage and associated factors among children aged 12-23 months in Mecha district, North West Ethiopia: A cross-sectional study. 2014;2(4):3428.

15. Kassahun MB, Biks GA, Teferra AS. Level of immunization coverage and associated factors among children aged 12 - 23 months in Lay Armachiho District, North Gondar Zone, Northwest Ethiopia: a community based cross sectional study. BMC Res Notes. BioMed Central; 2015;1-10.

16. Negussie A, Kassahun W, Assegid S, Hagan AK. Factors associated with incomplete childhood immunization in Arbegona district, southern Ethiopia: a case - control study. BMC Public Health [Internet]. BMC Public Health; 2016;1-9. Available from: http://dx.doi.org/10.1186/s12889-015-2678- 
17. Bugvi AS, Rahat R, Zakar R, Zakar MZ, Fischer F. Factors associated with non-utilization of child immunization in Pakistan: evidence from the Demographic and Health Survey 2006-07. BMC Public Health [Internet]. BMC Public Health; 2014;14(1):1-7.

18. Funmilayo A. Determinants of full child immunization among 12-23 months old in Nigeria. 2013; (6812-12).

19. Elias L.Worku D.An assessment of child immunization coverage and its determinants in Sinana District, Southeast Ethiopia. Biomed central.2015, 15:31

20. Abyot GA.Digsu NK.etal.Access O. Determinants of default to fully completion of immunization among children aged 12 to 23 months in south Ethiopia: unmatched case-control study. 2016;8688:1-8.

21. Abadi Girmay. Abel Fikadu Daddi. Full Immunization Coverage and Associated Factors among Children Aged 12-23 Months in a Hard-to-Reach Areas of Ethiopia, International journal of Pediatrics.2019

\section{Tables}

Table 1: Risk factors used for sample size calculation of "risk factors associated with non vaccination against measles in Yirgachefe woreda, Ethiopia, 2016.

\begin{tabular}{|c|c|c|c|c|c|}
\hline Risk Factor & $\begin{array}{l}\text { Proportion of } \\
\text { cases }\end{array}$ & $\begin{array}{l}\text { Proportion of } \\
\text { controls }\end{array}$ & $\begin{array}{l}\text { Odds } \\
\text { Ratio }\end{array}$ & $\begin{array}{l}\text { Calculated } \\
\text { sample size }\end{array}$ & References \\
\hline $\begin{array}{l}\text { Knowledge of the mother about child } \\
\text { Immunization }\end{array}$ & $11.5 \%$ & $2.30 \%$ & 5.51 & 478 & (16) \\
\hline $\begin{array}{l}\text { Mothers negative perception about } \\
\text { vaccine side effects }\end{array}$ & 57.3 & 32.2 & 2.83 & 251 & (7) \\
\hline Antenatal care & $48.5 \%$ & $27 \%$ & 2.55 & 320 & $(7)$ \\
\hline Post natal care & $68 \%$ & $44 \%$ & 2.7 & 277 & (19) \\
\hline
\end{tabular}

Table 2: socio-demographic factors related to non vaccination against measles in Yirgachefe district, Southern Ethiopia, 2016 


\begin{tabular}{|c|c|c|c|c|c|}
\hline Variables & Category & Cases & Controls & Crude OR(95\% CI) & $p$ value \\
\hline \multirow[t]{2}{*}{ Religion } & Protestant & $85(85 \%)$ & $187(93.5 \%)$ & 1 & \\
\hline & Other & $15(15 \%)$ & $13(6.5 \%)$ & $2.54(1.16-5.57)$ & 0.02 \\
\hline \multirow[t]{2}{*}{ Ethnicity } & Gedeo & $98(98 \%)$ & $197(98.5 \%)$ & 1 & \\
\hline & Other & $2(2 \%)$ & $3(1.5 \%)$ & $1.34(0.22-8.15)$ & 0.75 \\
\hline \multirow[t]{3}{*}{ Family income } & $\geq 1000$ & $5(5 \%)$ & $6(3 \%)$ & 1 & \\
\hline & $500-1000$ & $17(17 \%)$ & $38(19 \%)$ & $0.54(0.14-2.00)$ & 0.36 \\
\hline & $\leq 500$ & $78(78 \%)$ & $156(78 \%)$ & $0.60(0.18-2.03)$ & 0.41 \\
\hline \multirow[t]{5}{*}{ Mother's/Caretaker's occupation } & House wife & $68(68 \%)$ & $113(56.5 \%)$ & 1 & \\
\hline & Student & $2(2 \%)$ & $10(5 \%)$ & $0.33(0.71-1.56)$ & 0.16 \\
\hline & Merchant & $5(5 \%)$ & $19(9.5 \%)$ & $0.44(0.16-1.23)$ & 0.12 \\
\hline & Farmer & $23(23 \%)$ & $54(27 \%)$ & $0.71(0.40-1.26)$ & 0.24 \\
\hline & Other & $2(2 \%)$ & $4(2 \%)$ & $0.83(0.15-4.66)$ & 0.83 \\
\hline \multirow[t]{2}{*}{ Mother's/Caretaker's educational status } & Literate & $30(30 \%)$ & $75(37.5 \%)$ & 1 & \\
\hline & Illiterate & $70(70 \%)$ & $125(62.5 \%)$ & $1.40(0.84-2.34)$ & 0.20 \\
\hline \multirow[t]{2}{*}{ Mother's/Caretaker's marital status } & Married & $99(99 \%)$ & $199(995 \%)$ & 1 & \\
\hline & Other & $1(1 \%)$ & $1(0.5 \%)$ & $2.01(0.12-32.47)$ & 0.62 \\
\hline \multirow[t]{2}{*}{ Sex of the child } & Male & $57(57 \%)$ & $109(54.5 \%)$ & 1 & \\
\hline & Female & $43(43 \%)$ & $91(45.5 \%)$ & $0.90(0.56-1.47)$ & 0.68 \\
\hline \multirow[t]{2}{*}{ Age of the child } & 12-18 months & $57(57 \%)$ & $105(52.5 \%)$ & 1 & \\
\hline & 19-23 months & $43(43 \%)$ & $95(47.5 \%)$ & $0.83(0.51-1.35)$ & 0.46 \\
\hline \multirow[t]{3}{*}{ Birth order } & 1 & $25(25 \%)$ & $55(27.5 \%)$ & 1 & \\
\hline & $2-3$ & $35(35 \%)$ & $68(34 \%)$ & $1.13(0.61-2.11)$ & 0.70 \\
\hline & $\geq 4$ & $40(40 \%)$ & $77(38.5 \%)$ & $1.14(0.62-2.1)$ & 0.70 \\
\hline \multirow[t]{2}{*}{ Family size } & $<5$ & $55(55 \%)$ & $116(58 \%)$ & 1 & \\
\hline & $>5$ & $45(45 \%)$ & $84(42 \%)$ & $1.13(0.70-1.83)$ & 0.62 \\
\hline
\end{tabular}

Table 3: Maternal behavior related to non vaccination against measles in Yirgachefe district, Southern Ethiopia, 2016 


\begin{tabular}{|c|c|c|c|c|c|}
\hline Variables & Category & $\begin{array}{c}\text { Cases No } \\
(\%)\end{array}$ & $\begin{array}{c}\text { Controls No } \\
(\%)\end{array}$ & $\begin{array}{l}\text { Crude OR(95\% } \\
\text { CI) }\end{array}$ & $p$ value \\
\hline \multirow{3}{*}{$\begin{array}{l}\text { Ever heard about measles } \\
\text { vaccination }\end{array}$} & Yes & $72(72 \%)$ & $185(92.5 \%)$ & 1 & \\
\hline & No & $28(28 \%)$ & $15(7.5 \%)$ & $4.80(2.42-9.50)$ & $0.00 *$ \\
\hline & Health professionals & $62(86.1 \%)$ & $170(92.9 \%)$ & 1 & \\
\hline \multirow{3}{*}{$\begin{array}{l}\text { Where did you get the } \\
\text { information }\end{array}$} & Mass media & $6(8.3 \%)$ & $8(4.4 \%)$ & $2.06(0.69-6.16)$ & 0.20 \\
\hline & Other & $4(5.6 \%)$ & $5(2.7 \%)$ & $2.19(0.57-8.43)$ & 0.25 \\
\hline & Yes & $26(26 \%)$ & $152(76 \%)$ & 1 & \\
\hline \multirow[t]{2}{*}{$\begin{array}{l}\text { Should all children be } \\
\text { vaccinated }\end{array}$} & No & $74(74 \%)$ & $48(24 \%)$ & $\begin{array}{l}9.01(5.19- \\
15.66)\end{array}$ & $0.00 *$ \\
\hline & At 9 months & $31(31 \%)$ & $147(73.5 \%)$ & 1 & \\
\hline \multirow[t]{2}{*}{ The right age of vaccination } & Didn't know & $69(69 \%)$ & $53(26.5 \%)$ & $\begin{array}{l}6.17(3.64- \\
10.46)\end{array}$ & $0.00 *$ \\
\hline & Yes & $70(70 \%)$ & $191(95.5 \%)$ & 1 & \\
\hline \multirow[t]{2}{*}{ Is vaccinating a child important? } & $\begin{array}{c}\text { No } \\
\text { To prevent from }\end{array}$ & $30(30 \%)$ & $9(4.5 \%)$ & $9.1(4.11-20.11)$ & $0.00 *$ \\
\hline & disease & $48(48 \%)$ & $154(77 \%)$ & 1 & \\
\hline \multirow[t]{2}{*}{ Benefit of vaccination } & Didn't know & $52(52 \%)$ & $46(23 \%)$ & $3.63(2.17-6.05)$ & $0.00 *$ \\
\hline & Yes & $60(60 \%)$ & $184(92 \%)$ & $\begin{array}{c}1 \\
7.67(4.01-\end{array}$ & \\
\hline \multirow[t]{2}{*}{ Is measles vaccine preventable? } & No & $40(40 \%)$ & $16(8 \%)$ & 14.67) & $0.00 *$ \\
\hline & Yes & $65(65 \%)$ & $182(91 \%)$ & 1 & \\
\hline Is measles contagious? & No & $35(35 \%)$ & $18(9 \%)$ & $\begin{array}{c}5.44(2.89- \\
10.28) \\
\end{array}$ & $0.00 *$ \\
\hline
\end{tabular}

Table 4: Risk factors related to non vaccination against measles in Yirgachefe district, Southern Ethiopia, 2016 


\begin{tabular}{|c|c|c|c|c|c|}
\hline Variables & Category & $\begin{array}{c}\text { Cases No } \\
(\%)\end{array}$ & $\begin{array}{c}\text { Controls No } \\
\text { (\%) }\end{array}$ & $\begin{array}{l}\text { Crude OR }(95 \% \\
\text { CI })\end{array}$ & $p$ value \\
\hline \multirow{2}{*}{$\begin{array}{l}\text { Nearest HF provide routine immunization } \\
\text { service }\end{array}$} & Yes & $168(84 \%)$ & $78(78 \%)$ & 1 & \\
\hline & No & $32(16 \%)$ & $22(22 \%)$ & $1.48(0.81-2.71)$ & 0.20 \\
\hline \multirow[t]{2}{*}{ HEWs living in the kebele } & Yes & $199(99.5)$ & $96(96 \%)$ & 1 & \\
\hline & No & $1(0.5 \%)$ & $4(4 \%)$ & $\begin{array}{c}8.29(0.91- \\
75.19)\end{array}$ & 0.06 \\
\hline \multirow[t]{3}{*}{ Distance to reach the near HF } & 15-30 min & $33(44.6 \%)$ & $60(39 \%)$ & 1 & \\
\hline & $30 \mathrm{~min}-1 \mathrm{hr}$ & $23(31.1 \%)$ & $64(41.6 \%)$ & $0.65(0.34,1.24)$ & 0.19 \\
\hline & $>1 \mathrm{hr}$ & $18(24.3 \%)$ & $30(19.5 \%)$ & $1.09(0.53,2.25)$ & 0.81 \\
\hline \multirow[t]{2}{*}{ Availability of vaccination card } & Yes & $23(23 \%)$ & $158(79 \%)$ & 1 & \\
\hline & No & $77(77 \%)$ & $42(21 \%)$ & $\begin{array}{c}12.59(7.07- \\
22.42)\end{array}$ & $0.00 *$ \\
\hline \multirow[t]{2}{*}{ Faced delay in other EPI vaccinations } & Yes & $25(25 \%)$ & $65(32.5 \%)$ & $0.69(0.40-1.19)$ & 0.18 \\
\hline & No & $75(75 \%)$ & $135(67.5 \%)$ & 1 & \\
\hline \multirow{2}{*}{$\begin{array}{l}\text { Child ever vaccinated when they go to HF } \\
\text { for other purposes }\end{array}$} & Yes & $14(14 \%)$ & $74(37 \%)$ & 1 & \\
\hline & No & $86(86 \%)$ & $126(63 \%)$ & $3.61(1.92-6.8)$ & $0.00 *$ \\
\hline \multirow[t]{2}{*}{ Any child you took to HF but not vaccinated } & Yes & $17(17 \%)$ & $22(11 \%)$ & $1.66(0.84-3.29)$ & 0.15 \\
\hline & No & $83(83 \%)$ & $178(89 \%)$ & 1 & \\
\hline \multirow[t]{2}{*}{ ANC follow-up } & Yes & $34(34 \%)$ & $157(78.5 \%)$ & 1 & \\
\hline & No & $66(66 \%)$ & $43(21.5 \%)$ & $\begin{array}{c}7.09(4.16- \\
12.09)\end{array}$ & $0.00 *$ \\
\hline \multirow[t]{2}{*}{ Offered TT vaccination } & Yes & $42(42 \%)$ & $155(77.5 \%)$ & 1 & \\
\hline & No & $58(58 \%)$ & $45(22.5 \%)$ & $4.76(2.84-7.98)$ & $0.00 *$ \\
\hline \multirow[t]{2}{*}{ Place of Delivery } & $\begin{array}{c}\text { Health } \\
\text { Institution }\end{array}$ & $27(27 \%)$ & $102(51 \%)$ & 1 & \\
\hline & Home & $73(73 \%)$ & $98(49 \%)$ & $2.81(1.67-4.74)$ & $0.00 *$ \\
\hline \multirow[t]{2}{*}{ Who attended the delivery } & $\begin{array}{c}\text { Health } \\
\text { professional }\end{array}$ & $33(33 \%)$ & $102(51 \%)$ & 1 & \\
\hline & $\begin{array}{c}\text { Non- } \\
\text { professional }\end{array}$ & $67(67 \%)$ & $98(49 \%)$ & $2.11(1.28-3.49)$ & $0.003 *$ \\
\hline \multirow[t]{2}{*}{ PNC follow-up } & Yes & $30(30 \%)$ & $112(56 \%)$ & 1 & \\
\hline & No & $70(70 \%)$ & $88(44 \%)$ & $2.97(1.78-4.95)$ & $0.00 *$ \\
\hline
\end{tabular}

Table 5: Independent predictors of non vaccination against measles in Yirgachefe district, Southern Ethiopia, 2016

\begin{tabular}{cccccc}
\hline Variables & Category & Cases & Controls & COR(95\% CI) & AOR(95\% CI) \\
\hline \multirow{3}{*}{ Is vaccinating a child important? } & Yes & $70(70 \%)$ & $191(95.5 \%)$ & 1 & \\
& No & $30(30 \%)$ & $9(4.5 \%)$ & $9.10(4.11-20.11)$ & $6.81(1.56-29.64)$ \\
& Yes & $34(34 \%)$ & $157(78.5 \%)$ & 1 & \\
ANC follow up & No & $66(66 \%)$ & $43(21.5 \%)$ & $7.09(4.16-12.09)$ & $3.57(1.22-10.44)$ \\
& Yes & $26(26 \%)$ & $152(76 \%)$ & 1 & \\
Should all children be vaccinated? & No & $74(74 \%)$ & $48(24 \%)$ & $9.01(5.19-15.66)$ & $4.29(1.83-10.04)$ \\
& Yes & $65(65 \%)$ & $182(91 \%)$ & 1 & \\
Is measles contagious? & No & $35(35 \%)$ & $18(9 \%)$ & $5.44(2.89-10.28)$ & $8.97(3.15-25.58)$ \\
\hline
\end{tabular}




\section{Figures}

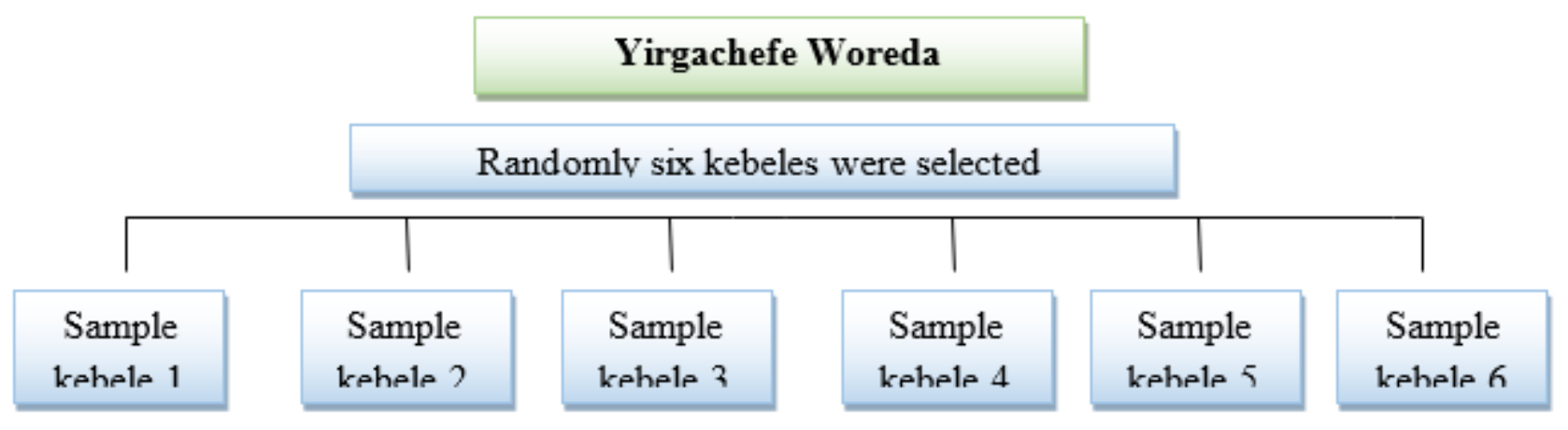

Lists of cases and controls were pulled out from the health extension worker's family folder in each kebele

Number of cases and controls to be included in the study for each kebeles was calculated using probability proportional to size sampling

Sample cases and controls were selected from the sampling frame randomly from each kebele

\section{Figure 1}

Sampling procedure of cases and controls for factors associated with non vaccination against measles in 12-23 months children, Yirgachefe woreda, 2016. 